\section{Análise da organização temporal do discurso na expressão da incerteza em português brasileiro}

Analysis of the temporal discourse organization in the expression of uncertainty in Brazilian Portuguese

Leandra Batista ANTUNES (UFOP) leandra@ufop.edu.br

Recebido em: 19 de jun. de 2020. Aceito em: 03 de set. de 2020.

\title{
00000000000
}

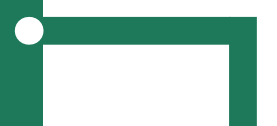

ANTUNES, Leandra Batista. Análise da organização temporal do discurso na expressão da incerteza em português brasileiro. Entrepalavras, Fortaleza, v. 11, n. 1, e1960, p. 1-23, jan.-abr./2021. DOI: $10.22168 / 2237-6321-11960$.

Resumo: A prosódia, enquanto elemento estruturador do discurso, cumpre várias funções na sociointeração (FÓNAGY, 2003). Entre elas está a de expressar intenções do locutor frente ao conteúdo enunciado. No caso da expressão da incerteza em diversas situações de interação (perguntas de conhecimentos gerais, jogos televisionados, questionário semiespontâneo), a prosódia desempenha papel fundamental. Alterações tanto na frequência fundamental e na intensidade quanto nos elementos que caracterizam a organização temporal do discurso (relacionados à duração, ou ao tempo de articulação do que é dito) dão pistas ao interlocutor sobre o falante ter ou não certeza frente ao que é dito (SILVA, 2008; ANTUNES; AUBERGÉ; SASA, 2014). Assim, buscamos descrever, nas situações de interação já mencionadas, como funcionam as taxas de elocução e articulação, a presença de pausas, de prolongamentos, de self-talk mais o tempo decorrido entre a pergunta e o início da resposta (tempo de latência), sempre comparando respostas em que se julgou que o locutor tinha certeza e aquelas em que se julgou como expressão de incerteza. As taxas de elocução e articulação foram menores nas respostas 
V. $11(1)$

$1-23$

jan-abr

2021

com incerteza (o que indica uma fala mais lenta), houve pausas, prolongamentos e self-talk somente na expressão da incerteza e o tempo para iniciar a resposta no caso das respostas com incerteza foi maior que naquelas com certeza. Nas situações discursivas diferentes, a construção da cena enunciativa pode influenciar no uso mais ou menos acentuado dos mesmos parâmetros prosódicos de duração para diferenciar a expressão de certeza daquela de incerteza.

Palavras-chave: Prosódia da incerteza. Situações de interação. Organização temporal do discurso. Afetos sociais.

Abstract: Prosody, as a structuring element of discourse, fulfills several functions in social interaction (FÓNAGY, 2003). Among them, there is one about expressing the speaker's intentions regarding the enunciated content. In the case of the expression of uncertainty in different situations of interaction (general knowledge questions, televised games, semi-spontaneous interview), prosody plays a fundamental role. Changes that could happen both in the fundamental frequency and in the intensity and also in the elements that characterize the temporal organization of the speech (related to the duration, or the time of articulation of what is said) give clues to the interlocutor about whether the speaker is sure about what is said (SILVA, 2008; ANTUNES; AUBERGÉ; SASA, 2014). Thus, we intend to describe, in these interaction situations previously mentioned, when the pauses, self-talk and phonemes extension are present, as well as what was the delay time between the end of the question and the beginning of the answer, always comparing answers which the speaker was judged to be sure to answers which he/she was not sure. The speech rate was lower in the expression of uncertainty (which indicates slower speech pace at this attitude), there were pauses, self-talk and phonemes extension only in uncertainty responses, also, the delay time, in case of uncertain expressions, was greater than in cases of certainty. In different discoursive situations, the construction of the enunciative scene can influence the use more or less accentuated of the same prosodic parameters of duration to differentiate the expression of certainty from that of uncertainty.

Keywords: Prosody of uncertainty. Interactional situations. Temporal organization of the discourse. Social affects.

\section{Introdução}

Cada vez mais, na atualidade, concebe-se a linguagem como essencial à vida e à nossa própria construção e condição enquanto seres sociais. Desde as primeiras relações entre linguagem e sociedade, feitas por Bakhtin na década de 1950, evidenciando a profunda relação entre as atividades humanas e os gêneros do discurso produzidos (BAKHTIN, $1992^{1}$ ), o olhar para a enunciação passou a ser cada vez mais frequente e relevante. Silva e Sousa (2017) argumentam que entender a linguagem é entender mais sobre a existência humana. Nossas relações dependem da linguagem e da enunciação, dos interlocutores, do contexto em que as trocas linguísticas se dão.

\footnotetext{
${ }^{1}$ Embora o texto de Bakhtin tenha ficado um tempo sem tradução e tenha chegado ao português por meio da tradução da versão francesa na década de 1980, o original russo data da década de 1950.
} 
A sociointeração é construída por vários elementos sociais e linguísticos, que se entrelaçam. No caso dos elementos sociais, faz-se necessário considerar, para construção da enunciação e dos sentidos, quem são os interactantes, em que contexto estão, para quem o discurso é produzido, que tipo de situação de interação se constrói (mais ou menos tensa, mais ou menos monitorada), buscando entender o discurso como objeto cultural (FIORIN, 1990).

Entre os elementos linguísticos levados em consideração para a produção de sentidos na sociointeração, muitas vezes o olhar se volta para as palavras, a construção das frases, o gênero textual, ou seja, o material linguístico escrito ou falado, mas outros elementos essenciais para a construção do sentido nem sempre são levados em consideração. A prosódia, por exemplo, é um dos elementos linguísticos mais relevantes na sociointeração verbal oral (BARBOSA, 2012), mas nem sempre é estudada. Analistas do discurso e pragmaticistas começam a inserir a prosódia em suas análises, assim como prosodistas passaram a refletir mais sobre a construção do discurso. A prosódia tem uma relação estreita com a construção discursiva e de sentido do dito e por isso deveria ser mais bem explorada, colocando em foco as relações entre a construção da cena enunciativa, os elementos prosódicos utilizados e os possíveis significados construídos.

Entendemos prosódia como elementos da fala que se sobrepõem ao material segmental (sons), assim como definido por Couper-Kuhlen (1986), compreendendo o volume, a acentuação, a melodia da fala e seus elementos temporais (pausas, velocidade de fala) ${ }^{2}$. A definição de Barbosa e Madureira (2015, p. 197) para prosódia se relaciona à "coordenação da sequência de gestos articulatórios correlatos da cadeia fônica, controlados pelas intenções comunicativas do falante". A partir dessa definição, nota-se que a prosódia não somente indica, mas às vezes por si só determina a intenção do falante - perguntar, afirmar, ordenar, impor-se, duvidar - (MORAES, 1993) e participa diretamente, pois, da construção do discurso, moldando nossa enunciação. É a prosódia que imprime a "o que se fala" um "jeito de falar", que pode ser intencional ou não por parte do locutor, e que chegará ou não a ser percebido pelo interlocutor (BARBOSA; MADUREIRA, 2015).

\footnotetext{
${ }^{2}$ Há outros elementos suprassegmentais, como a nasalidade, ou o tom nas línguas tonais, que não foram considerados aqui por se relacionarem diretamente com os fonemas dos sistemas linguísticos.
} 
V. 11 (1)

1-23

jan-abr

2021

Dada sua importância na construção do discurso e dos sentidos, podem ser apontadas várias funções desempenhadas pela prosódia no discurso falado3. Fónagy (2003) listou 15 funções para a prosódia; dentre essas funções, destacamos duas: a de indicar a modalidade da frase (se é interrogativa, declarativa, imperativa...) e a de expressar intenções, atitudes e emoções dos falantes (o 'jeito de falar' uma frase, que pode denotar raiva, tristeza, convencimento, certeza, possibilidade etc.). A essas duas funções, o autor ajunta outras, como a segmentação da fala em unidades menores, ou a proeminência ou o foco de um termo específico, também listadas por Barbosa e Madureira (2015).

Embora sejam muitas as funções prosódicas, e muitas delas foram ou estão sendo estudadas por pesquisadores da linguística, esse trabalho se volta para a função expressiva da prosódia. É por meio da prosódia que demonstramos nossas intenções frente ao que dizemos ou em relação ao nosso interlocutor. Podemos tomar o mesmo material linguístico (uma frase, por exemplo) e pronunciarmos este material de modo a denotar certeza, incerteza, obviedade (intenções que se relacionam ao conteúdo da frase) ou podemos pronunciá-lo com autoridade, com humildade ou mesmo seduzindo (intenções que tomamos frente ao interlocutor). Na fonética, esses afetos expressos no dito foram denominados, inicialmente, atitudes do locutor (COUPERKUHLEN, 1986), sendo atitudes proposicionais as que se referem ao conteúdo e atitudes sociais as que se referem ao interlocutor (MORAES, 2011). Com a (im)possibilidade de separar categoricamente atitudes do locutor de emoções (classificadas como uma reação automática do indivíduo, como medo, alegria, nojo), mesmo apesar de tentativas, como as de Aubergé (2002) e Wichmann (2002), ou de diferenciar atitudes de outras expressões, como o humor e até traços de personalidade, o termo atualmente utilizado para designar todos esses "sentimentos" expressos na fala é afetos sociais. Esses afetos se relacionam à expressividade controlada pelo falante e, portanto, voluntária. Segundo Mac et al. (2012), os afetos sociais são a parte mais importante da interação verbal face a face, ligados à cultura e ao sistema linguístico, e carregam intenções e pontos de vista do locutor (como surpresa, confirmação), bem como podem fornecer índices a respeito da interação (por exemplo, na polidez) ou informações contextuais

\footnotetext{
${ }^{3}$ Focalizamos, neste artigo, o discurso oral, uma vez que é o objeto dessa pesquisa, mas a prosódia também atua na leitura, por exemplo, determinando a segmentação de constituintes que possibilita construção de sentidos para o texto (cf. FODOR, 2002; FONSECA, 2008.).
} 
(por exemplo, no caráter público ou privado de uma conversa). É essa expressividade que será o foco deste trabalho ao estudarmos os afetos sociais certeza e incerteza4

Estudos prévios analisam a expressão de incerteza na atuação, comparando-a à certeza atuada e/ou à leitura neutra em português brasileiro (ex. SILVA, 2008; AZEVEDO, 2007). Poucos trabalhos se voltam para a expressão espontânea da incerteza (exceção aos trabalhos de ANTUNES; AUBERGÉ; SASSA, 2014; ANTUNES; AUBERGÉ, 2015, que analisaram prosodicamente a certeza e a incerteza na fala semiespontânea). Pensando no papel da prosódia como elemento fundamental à construção de sentidos nos afetos sociais certeza e incerteza, temos por objetivo analisar os elementos temporais (tempo de latência, pausas, prolongamentos, velocidade de fala, presença de selftalk) na expressão da incerteza em três situações discursivas diferentes, as quais consideramos situações de interação com fala semiespontânea produzida. Essas situações foram: perguntas de conhecimentos gerais feitas por um robô (corpus BotEmbauche, de ANTUNES; AUBERGÉ; SASA, 2014); respostas espontâneas ao questionário ALiB - Atlas Linguístico do Brasil (projeto sediado na UFBA, presidido atualmente por Profa. Dra. Jacyra Andrade Mota); respostas a perguntas em jogos televisionados, transmitidos em TV aberta e disponíveis no canal de armazenamento de vídeos YouTube ${ }^{\circledR}$. Como cada uma das enunciações analisadas tem suas particularidades, o segundo objetivo deste artigo é investigar se os mesmos elementos prosódicos são usados para expressar incerteza nessas diversas situações de interação, em virtude das diferentes cenas enunciativas construídas nessas situações.

\section{Elementos prosódicos e estudo acústico da prosódia}

A prosódia pode ser estudada sob vários pontos de vista. O ponto de vista da percepção foi muito utilizado no início do século passado. Descrições prosódicas envolviam principalmente a descrição melódica de frases isoladas (ex. PIKE, 1945; HALLIDAY, 1967). Posteriormente, com a possibilidade de uma análise instrumental, as propriedades acústicas dos enunciados orais começaram a ser exploradas. Diferente das descrições prosódicas feitas de oitiva, que priorizavam somente a melodia, a análise acústica das frases permitiu estudar a prosódia de

\footnotetext{
${ }^{4}$ Apesar de alguns autores diferenciarem incerteza de dúvida (ex. SILVA, 2008), neste trabalho não faremos distinção entre esses rótulos, mas optamos por utilizar apenas incerteza para a atitude de não saber, não estar certo, hesitar, duvidar.
} 
V. 11 (1)

1-23

jan-abr

2021 forma pluriparamétrica, estabelecendo como três parâmetros prosódicos fundamentais a frequência fundamental $\left(\mathrm{f}_{0}\right)$, a duração e a intensidade (CRYSTAL, 1969).

A frequência fundamental relaciona-se à configuração das pregas vocais e sua frequência de vibração, dada em ciclos por segundo (Hertz - Hz). As variações nesse parâmetro nos dão a percepção da alternância entre grave e agudo. Também pode ser medida em semitons, unidade que tem sido muito utilizada porque se aproxima mais de nossa percepção (BARBOSA; MADUREIRA, 2015).

Em relação à duração, as medidas realizadas referemse ao tempo de realização das unidades, sejam fones, sílabas ou constituintes maiores. A duração participa de nossa percepção de uma fala mais lenta ou mais rápida, em termos de velocidade de fala (taxas de articulação, elocução), mas também no que se refere à presença e duração de pausas, sejam silenciosas ou preenchidas, e à presença de prolongamentos (em fones ou sílabas). As medidas de duração são feitas em segundos (s) ou milissegundos (ms), conforme o tamanho da unidade que quantificamos.

A intensidade se relaciona ao que percebemos como volume da voz, da fala. Pronúncia de sentenças, sílabas ou outras unidades com volume maior ou menor auxiliam a construir foco, ênfase, entre outros sentidos. A medida desse parâmetro é feita em decibéis ( $d B)$, uma unidade relativa de medida de pressão da onda sonora.

$\mathrm{Na}$ análise prosódica, os três parâmetros são explorados na construção de sentidos. Em relação à incerteza, estudos anteriores (como os de SILVA, 2008; AZEVEDO, 2007) apontaram alterações nesses três parâmetros para diferenciar certeza de incerteza. No caso deste artigo, optamos por explorar um pouco mais os elementos relacionados à duração, que podemos agrupar em torno da designação de organização temporal do discurso.

Organização temporal do discurso - fluência, hesitações, pausas, tipos de pausas

A organização temporal do discurso é composta por muitos elementos. Além da pronúncia de sons e sílabas em um determinado tempo, que dá a cadência ou a velocidade da fala, podemos incluir nessa organização as hesitações, pausas, compondo o que se chama, em geral, de fluência da fala (OLIVEIRA et al., 2007). 
Quando falamos em fluência, estamos nos referindo a muitos componentes. Não se pode esperar que o fluxo da fala seja contínuo, sem qualquer interrupção. Há pausas para respirar, pausas para (re)formular o discurso, além de uma série de disfluências, que ocorrem mesmo na fala considerada não patológica, que compreendem elementos tais como repetição em nível da palavra, falsos inícios corrigidos ou abandonados, pausas de diversos tipos e prolongamentos finais (OLIVEIRA et al., 2007). A frequência e a duração desses elementos podem influenciar na construção de sentidos.

As pausas inseridas na fala podem ser silenciosas ou preenchidas (estas podem ser chamadas de hesitações). No caso das pausas preenchidas, em português brasileiro, esse preenchimento é feito muitas vezes pela vogal "e" alongada ou também pela vogal neutra "schwa" alongada, com ou sem nasalidade (representadas, nas transcrições ortográficas, por é, eh ou por ah, an, respectivamente) (MERLO; BARBOSA, 2012). Segundo Zellner (1994), pausas são mais perceptíveis se cumprem papel na construção de sentido da sentença; se têm duração mínima entre 200 e 250 ms; se indicam hesitação. Uma das funções da pausa, aquela que mais nos interessa nesta pesquisa, é a de indicar que uma atividade cognitiva de processamento está em curso. As pausas são utilizadas para proporcionar tempo adicional durante o qual o material linguístico (segmental e suprassegmental) é preparado para ser dito. Quanto mais complexo o processamento cognitivo, mais propensão a pausas, a hesitações e mesmo a gaguejar (ZELLNER, 1994). Isso se aplica, então, ao nosso objeto, uma vez que, na expressão de incerteza, esperamos uma atividade cognitiva maior para processar e elaborar a resposta.

Outro elemento da análise temporal do discurso é a velocidade de fala, medida em unidades de fala (quantidade de sílabas, palavras) divididas por unidades de tempo (minutos, segundos). Essas medidas, chamadas taxa de articulação e de elocução, levam em consideração o número de sílabas pronunciadas divididas pela duração do que foi pronunciado no enunciado, com ou sem pausas. (GROSJEAN; DESCHAMPS, 1975).

\section{Características prosódicas da expressão de certeza e de incerteza}

O contraste prosódico entre as expressões da certeza e da incerteza tem sido pesquisado e demonstrado em várias línguas; 
V. 11 (1)

$1-23$

jan-abr

2021

retomamos aqui um estudo feito para o holandês e quatro estudos feitos para o português brasileiro.

Krahmer e Swerts (2005) descrevem experimentos feitos para caracterizar a expressão da incerteza em holandês em respostas a questões factuais (exemplo de pergunta do experimento: "Quem escreveu Fausto?"). As respostas dadas às questões foram classificadas pelos pesquisadores como expressas com certeza ou com incerteza e, a partir disso, foram analisados os seguintes parâmetros: presença ou ausência de preenchimentos (pausas preenchidas), tempo para iniciar a resposta (latência), entonação ascendente (como se a resposta fosse uma pergunta), repetição da pergunta ou qualquer fala para si mesmo que o locutor faz antes de responder (designada por self-talk). A esses parâmetros foi adicionada a análise de movimentos de sobrancelha, sorrisos e expressão facial marcada (funny face), referentes à prosódia facial dos locutores na resposta.

Os resultados demonstraram haver, na expressão da incerteza, maior presença de preenchimentos e self-talk, maior tempo de latência e ocorrência de entonação ascendente, se comparada à certeza. Quanto à expressão facial, foram encontrados movimentos de sobrancelha, sorrisos e funny face somente nas respostas com incerteza.

Silva (2008) estudou a expressão da certeza e da dúvida ${ }^{5}$ no português brasileiro. Azevedo (2007) desenvolveu um trabalho em que buscou caracterizar a expressão de certeza e de dúvida ${ }^{6}$ em indivíduos com doença de Parkinson idiopática. Ambas as autoras gravaram sentenças alvo, inseridas em situações que induziam à produção de um ou outro afeto social; Silva gravou atores e Azevedo gravou indivíduos idosos com patologia de Parkinson e um grupo controle sem distúrbios neurológicos ou de fala.

Como resultados, tanto Silva quanto Azevedo (retomamos aqui somente as expressões do grupo controle, para não introduzir o fator patológico da doença de Parkinson, que modifica a fala - essas foram as conclusões de Azevedo, 2007) apontam diferenças prosódicas importantes entre a certeza e a dúvida: na dúvida, os valores de $\mathrm{f}_{\mathrm{o}}$ são mais altos que na certeza; às vezes aparece um movimento final

\footnotetext{
${ }^{5}$ Neste trabalho, a autora utiliza o termo dúvida que, para ela, é diferente de incerteza. No entanto, como na maior parte de seu trabalho silva discute apenas as características da dúvida, optamos por apresentar o termo dúvida na retomada deste trabalho. Como dissemos anteriormente, o termo incerteza, pelo qual optamos, é considerado por nós um sinônimo de dúvida, termo usado por SILVA (2008).
}

${ }^{6}$ Azevedo também utiliza o termo dúvida em seu trabalho, por isso o reproduzimos aqui. 
de $\mathrm{f}_{\mathrm{o}}$ ascendente na dúvida; as durações são maiores na dúvida e há presença de pausas e prolongamentos na expressão desse afeto social; a intensidade na dúvida é normalmente menor que na certeza.

Antunes, Aubergé e Sasa (2014) fizeram um estudo da expressão espontânea da certeza e da incerteza em respostas a questões de conhecimento geral. A fim de obter respostas com certeza e incerteza, as autoras fizeram um rol de questões fáceis, médias e difíceis, a fim de que houvesse variação nas respostas quanto aos afetos sociais expressados. Foram convidados a responder a essas questões 10 estudantes universitários de diversas cidades do Brasil7.

Foram feitos registros de áudio e vídeo das respostas dadas. Essas respostas foram julgadas pelos próprios informantes, em momento posterior à gravação, quanto à expressão da certeza e da incerteza. A análise prosódica das respostas envolveu expressões faciais (prosódia gestual), tais como alterações na direção do olhar, movimentos na boca e nas sobrancelhas, e o áudio dos enunciados, sendo analisados os parâmetros prosódicos de duração, $\mathrm{f}_{0}$ e intensidade.

Os resultados mostraram que a expressão de incerteza tem um tempo de latência maior que o da certeza, maior presença de pausas e prolongamentos e movimento final de $\mathrm{f}_{0}$ ascendente. Em relação à taxa de articulação, a fala na incerteza apresentou valores menores que na certeza, o que indica que é mais lenta. Também foram observadas na incerteza sílabas com duração maior que na certeza.

Em uma extensão do estudo do mesmo corpus de Antunes, Aubergé e Sasa (2004), Antunes e Aubergé (2015) ajuntaram, ao estudo da expressão espontânea da certeza e da incerteza, a expressão atuada desses mesmos afetos sociais. A atuação foi feita pelos mesmos locutores, com as mesmas respostas que tinham dado anteriormente, simulando primeiro uma resposta com certeza e depois uma resposta com incerteza. O objetivo desse estudo foi verificar se fala espontânea e atuada de certeza e incerteza utilizavam os mesmos parâmetros prosódicos para sua expressão.

Na comparação entre fala espontânea e atuada, certeza e incerteza apresentaram diferença de valores para os mesmos parâmetros prosódicos, porém as autoras apontam que a atuação desses afetos funciona como uma caricatura: há traços realçados e outros apagados

\footnotetext{
7 Embora houvesse locutores de várias localidades envolvidos neste estudo, as autoras não encontraram nenhuma diferença de expressividade que pudesse estar ligada à origem geográfica dos informantes.
} 
V. $11(1)$

$1-23$

jan-abr

2021

na atuação. A variação de $\mathrm{f}_{0}$, por exemplo, apresenta diferença maior entre certeza e incerteza na fala espontânea, já os movimentos de $\mathrm{f}_{0}$ são mais expressivos na fala atuada.

\section{Dados utilizados para o estudo}

Os estudos anteriormente feitos para descrever características prosódicas da certeza e da incerteza em português brasileiro não levaram em consideração as condições discursivas de cada situação de interação. A fim de fazer um estudo comparativo de situações interacionais diferentes para expressão da certeza e da incerteza, tomamos dados de três situações de interação, com cenas enunciativas compostas de maneira diversa. Os dados aqui analisados vieram de três fontes: respostas a questões de conhecimentos gerais, respostas a um questionário (semidirecionado) e, por fim, respostas a questões de conhecimentos gerais em um jogo televisionado. Descrevemos a seguir cada uma delas, fazendo observações quanto à construção de cada cena enunciativa.

Na primeira situação, respostas a questões de conhecimentos gerais, tomamos como base de análise o corpus BotEmbauche (ANTUNES; AUBERGÉ; SASA, 2014). Nesse corpus, doravante denominado BotE, o locutor foi convidado a avaliar o sistema de um robô que estava sendo desenvolvido para fazer entrevistas de emprego. Esse locutor foi informado de que responderia à entrevista de emprego feita pelo robô para avaliá-lo enquanto entrevistador. Foi dito ainda que, para que o robô pudesse reconhecer a voz do locutor na entrevista, seriam feitas perguntas de conhecimentos gerais antes da entrevista de emprego. $\mathrm{O}$ informante não sabia que estava sendo gravado (isso só foi revelado depois, e os dados foram utilizados apenas mediante o consentimento livre e esclarecido do locutor).

A cena enunciativa aqui analisada se constituiu, então, de um pequeno robô, operado por comandos em uma sala à parte (fato que locutor desconhecia), e, em frente a ele, o locutor. Exemplos das questões feitas são "Lisboa é a capital de que país?" e "Qual a maior glândula do corpo humano?". Foram feitas 12 perguntas a cada um dos participantes, com diversos graus de dificuldade, para propiciar respostas com certeza ou com incerteza. Devido à situação de interação com um robô e à tensão de responder a questões de conhecimentos gerais (algumas cujas respostas são conhecidas, outras não), a fala não 
pode ser julgada espontânea aqui, mas, como o locutor não sofre pressão de ter que acertar as questões nem sabe que está sendo gravado, a fala se aproxima da espontânea, por isso a consideramos semiespontânea.

Foram analisados, neste trabalho, respostas de 6 locutores do corpus BotE: três homens e três mulheres, estudantes universitários, com idades entre 20 e 25 anos, nascidos na região sudeste do Brasil. Como cada resposta poderia ter sido dada com certeza ou com incerteza, foram escolhidas as respostas mais representativas desses dois afetos, ou seja, aquelas em que o próprio locutor afirmou categoricamente ter respondido com certeza ou com incerteza, e isso resultou em 29 respostas com certeza e 22 com incerteza para análise.

Quanto aos dados do questionário do Atlas Linguístico do Brasil - AliB, a situação de interação se deu quando foram gravadas as entrevistas do projeto. Esta investigação, dirigida pela profa. Jacyra Andrade Mota da Universidade Federal da Bahia, tem por objetivo investigar a variação linguística em 250 localidades brasileiras. As entrevistas foram feitas sempre por um membro que compõe a equipe do ALiB, que iniciava solicitando os dados pessoais do locutor, sua família, suas experiências, para posteriormente iniciar a entrevista focada em aspectos linguísticos ${ }^{8}$. O projeto procura abranger várias áreas de estudo de variação linguística: fonético-fonológica, morfológica, semânticolexical, pragmática. Para este trabalho foram utilizadas respostas dadas ao questionário fonético-fonológico e ao semântico-lexical ${ }^{9}$ do ALiB.

A cena enunciativa dessas entrevistas consiste em um diálogo (os entrevistadores do ALiB fazem o possível para entrar na comunidade e ganhar alguma intimidade com o locutor antes de começarem a aplicação do questionário) entre entrevistador e entrevistado. No início da entrevista, enquanto são feitas as perguntas pessoais de identificação, normalmente o locutor está mais tenso, principalmente por saber que está sendo gravado. No decorrer da aplicação dos questionários, no entanto, esta tensão vai diminuindo. A intenção, na realização do projeto ALiB, é construir um diálogo menos monitorado, em que as respostas sejam próximas àquilo que o informante usa no dia a dia, embora isso não exclua a possibilidade de influência da gravação e dos instrumentos para fazê-la na espontaneidade do que é falado pelos locutores.

\footnotetext{
${ }^{8}$ Não há um local em que esse corpus esteja disponível. Para trabalhar com a análise prosódica das respostas dadas por informantes das capitais da região sudeste, foi pedida uma autorização aos pesquisadores responsáveis, que nos cederam prontamente os dados, e, por isso, lhes agradecemos.
}

${ }_{9}$ Para informações complementares sobre o ALiB, acessar <https://alib.ufba.br/>. 
V. 11 (1)

1-23

jan-abr

2021

Para análise feita aqui, foram utilizadas respostas dadas a questões dos questionários fonético-fonológico e semântico-lexical do ALiB por informantes nascidos e criados nas capitais do sudeste (8 informantes ao todo, sendo um homem e uma mulher de cada capital, todos com curso universitário e faixa etária entre 18 e 30 anos). No questionário fonético-fonológico, o entrevistador faz perguntas direcionadas, com uma resposta específica (ex.: "O que é que se tira da banana para comer?"; resposta esperada: "a casca"); e, no questionário semântico-lexical, as perguntas são sobre como o informante denomina objetos, alimentos, fenômenos do tempo, entre outras categorias (ex.: "Como você chama aquela fruta, parecida com a laranja, que vocêdescasca com a mão?"; respostas esperadas: mexerica, tangerina, bergamota etc.). As respostas dadas pelos informantes podem ser ditas com certeza ou com incerteza, pelo fato de conhecerem ou desconhecem a resposta ou demandarem maior ou menor tempo para se lembrarem dela. Foram ouvidas as respostas dadas pelos 8 locutores e foram tomadas, para cada informante, cinco respostas com certeza e cinco com incerteza, assim rotuladas pela pesquisadora e mais um pesquisador especialista na área, ambos nascidos na região sudeste do país, segundo sua percepção de certeza ou incerteza como falantes nativos do português brasileiro. No total, 80 respostas foram analisadas, sendo 40 com cada afeto social investigado nesta pesquisa.

Por fim foram analisadas respostas a um jogo televisionado: "Pergunte aos Universitários". Nessa situação de interação, o apresentador do programa, Sílvio Santos, faz perguntas, enviadas pelos espectadores, a estudantes universitários. O objetivo do jogo é responder, com até 4 erros, 490 perguntas, a fim de ganhar meio milhão de reais. Entre as regras do jogo está a de responder à pergunta em até 10 segundos, pois, se esse tempo for ultrapassado, a resposta será considerada errada.

A cena enunciativa, nesse programa, doravante denominado PU, é constituída por quatro interactantes: i) o apresentador, Sílvio Santos, que fica de pé; ii) o universitário que está jogando, que fica em pé atrás de um púlpito e de frente para o apresentador; iii) outro universitário, sentado de frente para a câmera, com Sílvio Santos a um lado e, ao outro, o universitário que está jogando; iv) o público, que assiste ao jogo no auditório ou por meio da transmissão televisiva. O universitário que respondeu a mais perguntas, até o momento do jogo, fica sentado de frente para a câmera, sem participar do jogo. Sua 
presença lhe permite aumentar o valor ganho (a cada semana em que participa do programa esse universitário ganha mil reais). Nessa situação de interação, o universitário que joga sofre a tensão de responder a um apresentador de TV conhecido em todo o Brasil, de se expor frente a um público telespectador e a tensão de ter que acertar as respostas para ganhar o prêmio. Ajunte-se a isso a imposição de responder cada pergunta em até 10 segundos.

No caso deste programa, tomamos 4 de suas edições, televisionadas em julho e agosto de 2015. A partir dos vídeos baixados do YouTube, salvamos o som em formato mp3 e analisamos as respostas de 4 locutores, todos de São Paulo, sendo 2 homens e 2 mulheres, com idade aproximada de 20 a 30 anos. Novamente, como o nível de dificuldade das questões é muito variável, aparecem respostas com certeza e com incerteza. Foram selecionadas 40 respostas com certeza (10 de cada locutor) e 29 com incerteza (sete de três locutores, oito de um locutor). Esse rótulo de respostas com certeza ou incerteza foi atribuído pela pesquisadora, segundo sua percepção como falante nativa do português brasileiro.

Esses três corpora apresentam situações de interlocução e cenas enunciativas variadas. Todos foram considerados como fala semiespontânea, uma vez que, apesar de haver alguma tensão nas três situações de interação, a expressão de certeza ou incerteza não é controlada pelo pesquisador (não há imposição de um ou outro modo de responder, isso é espontaneamente escolhido pelo locutor), então a expressão de incerteza ou de certeza pode ser considerada relativamente espontânea, já que o pesquisador não a determinou (BARBOSA, 2012). Também é importante lembrar que todas as perguntas foram respondidas em situações reais de sociointeração.

Os dados selecionados para essa investigação totalizaram 200 respostas, sendo 109 com certeza e 91 com incerteza. Descrevemos a seguir como foi feita a análise acústica desses dados.

\section{Análise acústica dos dados - mensuração dos elementos da organização temporal do discurso}

A análise acústica dos parâmetros ligados à organização temporal do discurso foi feita no software Praat ${ }^{10}$ (BOERSMA; WEENINK,

${ }^{10}$ Esse software é gratuito, de uso livre, e está disponível no endereço eletrônico <www.praat. org $>$. 
V. $11(1)$

$1-23$

jan-abr

2021

2019), cujo objetivo é permitir análises fonéticas por meio de estudo das propriedades acústicas do som. Cada uma das respostas escolhidas foi demarcada em seu contexto maior e teve sua análise feita de acordo com os seguintes parâmetros:

- Duração total do enunciado: tempo, medido em segundos, do final da pergunta-estímulo feita até o final da resposta dada pelo locutor. Esse tempo inclui o tempo de latência. Para realizar essa segmentação, assim como nas demais, o espectrograma foi observado. Assim, em conjunto com a audição do enunciado e a onda sonora, os limites foram estabelecidos por meio das propriedades físicas dos sons visíveis no espectrograma.

- Duração da elocução: tempo, medido em segundos, do início ao fim da produção das respostas (somente o tempo de fala na resposta).

- Tempo de latência: duração, em segundos, do final da pergunta até o início da resposta.

- Taxas de articulação e elocução: foram segmentadas e contadas as sílabas fonológicas realizadas foneticamente durante a resposta (para constituir uma sílaba, a composição mínima foi um núcleo vocálico, podendo ser estendida de modo a agrupar segmentos consonantais adjacentes pronunciados em conjunto com essa vogal). Quando vogais átonas não foram pronunciadas, a sílaba a que pertenciam não foi contada, mas as consoantes reagrupadas em torno da vogal seguinte pronunciada - ex.: se a pronúncia da palavra "estranho" foi feita sem a vogal "e" inicial, o segmento consonantal [s] foi agrupado à sílaba seguinte, "tra", e, em vez de contar duas sílabas "es-tra", foi computada apenas uma sílaba foneticamente pronunciada "stra". O número de sílabas pronunciadas foi dividido pela duração total do enunciado, incluindo tempo de latência e pausas, resultando na taxa de articulação. No caso da taxa de elocução, o cálculo foi feito dividindo o número de sílabas pronunciadas pela duração das respostas, sem considerar pausas e tempo de latência. Essas taxas são expressas em número de sílabas por segundo.

- Presença e duração de pausas (silenciosas ou preenchidas), de prolongamentos (de fones e sílabas) e de self-talk: foi 
anotado, em cada resposta, se havia pausas, prolongamentos e/ ou self-talk (repetição da pergunta, ou fala consigo) e, em caso afirmativo, a duração desses fenômenos foi medida. Pausas de todos os tamanhos e tipos foram inseridas nessa medição ${ }^{11}$.

Após ter feito essas análises, os resultados foram analisados estatisticamente no software Excel ${ }^{\circledR}$. Inicialmente foram calculadas as médias e desvios padrão dos valores aferidos para cada categoria. Na sequência, foram feitos testes T de Student, com intervalo de confiança de $95 \%$, para verificar se havia diferenças significativas entre as respostas dadas com certeza e incerteza nas três situações comunicativas analisadas.

\section{Resultados e discussões}

Duração total do enunciado e duração da elocução

Como as respostas analisadas têm material linguístico diferente, não há razão para apresentarmos aqui uma média de duração dos enunciados ou da duração das elocuções, seja para comparar a certeza e a incerteza, seja para comparar as respostas nas três diferentes situações discursivas. Essas medidas foram aqui utilizadas para o cálculo das taxas de articulação e de elocução, respectivamente. Dessa forma, foi possível verificar o quanto essas taxas variam, uma em relação à outra, na certeza e na incerteza e nas diferentes situações discursivas. Os resultados do cálculo das taxas de elocução e de articulação podem ser vistos na tabela 1.

Tabela 1 - Valor médio das taxas de elocução e articulação, em sílabas por segundo, das respostas com certeza e incerteza nas três situações discursivas estudadas

\begin{tabular}{c|cc|cc|cc} 
& \multicolumn{2}{|c|}{ PU } & \multicolumn{2}{c|}{ BotE } & \multicolumn{2}{c}{ ALiB } \\
\cline { 2 - 7 } Certeza & Tx Eloc. & Tx Artic. & Tx Eloc. & Tx Artic. & Tx Eloc. & Tx Artic. \\
\hline $\begin{array}{c}5,81 \text { síl/s } \\
(1,15)\end{array}$ & $\begin{array}{c}3,53 \mathrm{síl} / \mathrm{s} \\
(1,12)\end{array}$ & $\begin{array}{c}5,16 \mathrm{síl} / \mathrm{s} \\
(0,76)\end{array}$ & $\begin{array}{c}2,56 \mathrm{síl} / \mathrm{s} \\
(0,94)\end{array}$ & $\begin{array}{c}4,70 \mathrm{síl} / \mathrm{s} \\
(1,13)\end{array}$ & $\begin{array}{c}3,84 \mathrm{síl} / \mathrm{s} \\
(1,28)\end{array}$ \\
Incerteza & $\begin{array}{c}3,85 \mathrm{síl} / \mathrm{s} \\
(1,99)\end{array}$ & $\begin{array}{c}1,01 \mathrm{síl} / \mathrm{s} \\
(1,39)\end{array}$ & $\begin{array}{c}4,40 \mathrm{síl} / \mathrm{s} \\
(1,08)\end{array}$ & $\begin{array}{c}2,70 \mathrm{síl} / \mathrm{s} \\
(0,94)\end{array}$ & $\begin{array}{c}4,46 \mathrm{síl} / \mathrm{s} \\
(1,16)\end{array}$ & $\begin{array}{c}1,53 \mathrm{síl} / \mathrm{s} \\
(1,16)\end{array}$
\end{tabular}

Legenda: Tx Eloc. - Taxa de Elocução; Tx Artic. - Taxa de Articulação. O valor calculado aparece, em cada célula, seguido do desvio padrão da média entre parênteses.

Fonte: Elaborada pelo autor com dados da pesquisa.

${ }^{11} \mathrm{O}$ tempo de silêncio das oclusivas não foi contabilizado na duração das pausas silenciosas quando era o primeiro som a ocorrer após sua realização. Esse tempo foi também observado na segmentação para não ser marcado como pausa. 
V. 11 (1)

$1-23$

jan-abr

2021

É possível observar, em todas as situações discursivas analisadas, queas respostas com expressão de incerteza apresentam taxas de elocução e de articulação menores que as respostas com expressão de certeza, com exceção dos dados do ALiB para a taxa de elocução, que é praticamente igual nos dois afetos sociais estudados. Aqui cabem duas observações: i) as taxas de elocução e articulação são diferentes, tanto na certeza quanto na incerteza, ou seja, ao incorporarmos o tempo de latência (e as pausas, quando presentes), o número de sílabas por segundo cai nos dois afetos; ii) quando excluída a latência e a duração de pausas, a incerteza se apresenta com fala mais lenta que a certeza, já que a taxa de elocução é menor na incerteza, pois são pronunciadas menos sílabas por segundo neste afeto social. Em análise estatística inferencial, certeza e incerteza apresentaram diferenças significativas $(p<0,05)$. Esse resultado confirma o encontrado em estudos anteriores (SILVA, 2008; AZEVEDO, 2007; ANTUNES; AUBERGÉ; SASA, 2014).

Quanto às situações discursivas, foi possível observar as mesmas tendências nas três interações pesquisadas quanto à taxa de elocução: fala mais lenta na expressão de incerteza. A observação da taxa de articulação, porém, permite interpretar que há tendências similares para os corpora Pergunte aos Universitários e BotEmbauche; mas isso não ocorre com os dados do $\mathrm{ALiB}$, pois não se observou fala mais lenta na expressão da incerteza. Foi possível observar que os elementos que diferenciam certeza de incerteza no caso do ALiB não estão ligados à taxa de articulação. Esse resultado apresenta uma possível diferença entre a situação discursiva de responder a um questionário em que o locutor não pensa que deve dar uma resposta certa, em relação a outras situações em que, pelo tipo de perguntas feitas, ou mesmo pela situação (ganhar um jogo), o falante reconhece haver uma resposta correta, e é aquela que ele deve buscar.

Tempo de latência

Os tempos de latência medidos são apresentados no gráfico 1, por situação discursiva. 
Gráfico 1 - Tempo médio de latência, expresso em segundos, das respostas com certeza e incerteza nas três situações discursivas estudadas

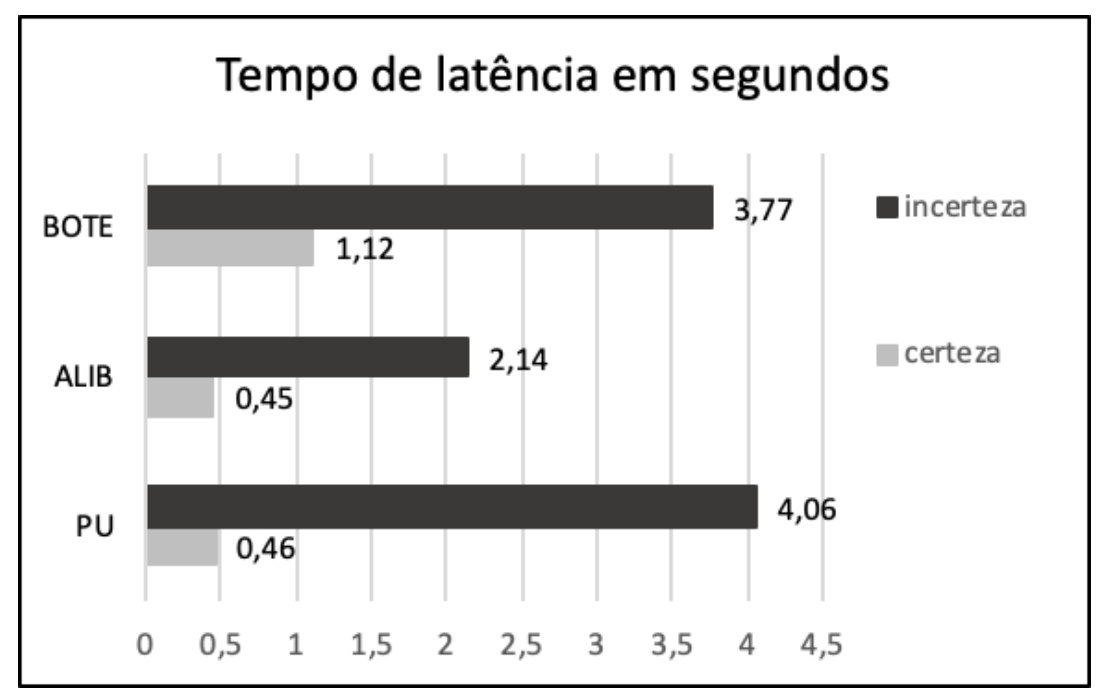

Fonte: Elaborado pelo autor com dados da pesquisa.

É possível notar, neste gráfico, que há diferenças entre as expressões da certeza, em que há pouco tempo de latência, e as expressões de incerteza, em que o tempo de latência é maior, corroborando os achados de pesquisas anteriores (KRAHMER; SWERTS, 2005; ANTUNES; AUBERGÉ; SASA, 2014; ANTUNES; AUBERGÉ, 2015). Em todas as três situações discursivas, a diferença do valor da latência na certeza e na incerteza foi estatisticamente significativa $(\mathrm{p}<0,05)$. Comparando as situações discursivas, no programa Pergunte aos Universitários, encontramos a maior diferença entre os tempos de latência nos afetos sociais analisados: o da certeza, com latência média de 0,46 s, perfaz apenas $11,3 \%$ daquele da incerteza, que apresentou média de 4,06 s. No caso do ALiB, o valor de latência na certeza, de 0,45 s, corresponde a $21 \%$ do tempo de latência da incerteza, que é de 2,14 s. Com a menor diferença de latência entre respostas com certeza e com incerteza, embora ainda significativa, estão os dados do BotEmbauche, em que a latência na certeza, com média de 1,12 s, representa 30,3\% da latência da incerteza, cuja média perfaz 3,7 s.

Essas diferenças entre as situações discursivas mostram que, nas situações discursivas diferentes, o mesmo recurso é usado para expressão da incerteza (maior tempo de latência), no entanto esse recurso pode ser usado de forma diferente. A obrigatoriedade de acertar a resposta para continuar no jogo pode levar os falantes do Pergunte aos Universitários a pararem para pensar quando não estão certos da resposta, ou seja, usam tempos de latência muito longos, às 
V. 11 (1)

1-23

jan-abr

2021

vezes beirando os dez segundos que têm para responder a uma questão. Essa latência longa na incerteza demonstra tempo de processamento cerebral para encontrar a resposta correta ou para confirmá-la consigo, o que está de acordo com Zellner (1994). No caso desse programa, cabe também observar que a situação é mais formal e está sendo transmitida pela TV, o que pode influenciar também no desejo do falante de não querer errar a resposta.

Presença e duração de prolongamentos de fones e sílabas, pausas e self-talk

Buscamos observar se havia, nas respostas dadas, prolongamento de fones e/ou sílabas, pausas (silenciosas ou preenchidas) e self-talk. Apresentamos, na tabela 2, as porcentagens encontradas de cada um desses recursos prosódicos nos enunciados analisados.

Tabela 2 - Número de respostas com pausas, prolongamentos e self talk /número total de dados e porcentagem de respostas com uso desses recursos na expressão da certeza e da incerteza nas três situações discursivas estudadas

\begin{tabular}{cccc|ccc|cccc} 
& \multicolumn{3}{c|}{ ALiB } & \multicolumn{3}{c|}{ BotE } & \multicolumn{3}{c}{ PU } \\
& pausa & prol. & s. talk & pausa & prol. & s. talk & pausa & prol. & s. talk \\
\hline \multirow{2}{*}{ Certeza } & $0 / 40$ & $0 / 40$ & $0 / 40$ & $1 / 29$ & $0 / 29$ & $1 / 29$ & 0 & 0 & 0 \\
& - & - & - & $3,4 \%$ & - & $3,4 \%$ & - & - & - \\
\multirow{2}{*}{ Incerteza } & $12 / 40$ & $0 / 40$ & $11 / 40$ & $13 / 22$ & $0 / 22$ & $8 / 22$ & $2 / 29$ & $6 / 29$ & $6 / 29$ \\
& $33 \%$ & - & $27,5 \%$ & $44,8 \%$ & - & $36,4 \%$ & $6,9 \%$ & $30,7 \%$ & $30,7 \%$
\end{tabular}

Legenda: prol. - prolongamentos; s.talk - self-talk. Em cada célula, aparece o número de ocorrências desse recurso/total de respostas analisadas e, entre parênteses, a porcentagem das respostas que apresentou o recurso, calculada por meio do número de ocorrências do recurso prosódico em relação ao número total de sentenças.

Fonte: Elaborada pelo autor com dados da pesquisa.

É possível visualizar, pelos dados da tabela 2, que a ocorrência de recursos prosódicos, como pausas, prolongamentos e self-talk praticamente não acontece na expressão da certeza. Em dois únicos casos, das 29 respostas com certeza do corpus BotEmbauche analisadas neste estudo, houve pausa (em uma resposta) e self-talk (em outra resposta). As respostas com incerteza, no entanto, fazem uso desses recursos com mais regularidade.

Nas três situações discursivas houve pausas em respostas com incerteza, sendo mais ocorrentes as pausas no corpus BotEmbauche (presentes em quase metade das respostas analisadas). Há que se 
considerar que, apesar de intencionarmos registrar todos os tipos de pausa, não houve pausas nem para respirar nem para estruturar unidades de processamento dos enunciados na expressão da certeza. Isso pode ser explicado porque as respostas analisadas são curtas (muitas vezes compostas de uma única palavra) e não há pausas somente para respiração ou estruturação. Embora tivéssemos proposto quantificar qualquer tipo de pausa, as pausas que mais ocorreram foram aquelas referentes ao tempo de processamento para elaborar / lembrar a resposta, já que ocorreram na expressão da incerteza, corroborando o dito por Zellner (1994), para quem quanto maior a cognição, maior o número de pausas e maior sua duração.

Quanto aos prolongamentos, no Pergunte aos Universitários houve prolongamentos de sílabas ou fones em 6 das 29 respostas com incerteza, perfazendo 30,7\% das respostas. Somente nessa situação discursiva os prolongamentos foram observados. Essa diferença pode ter ocorrido pela tensão nessa situação discursiva que, segundo nossa percepção, é a mais monitorada das três, o que exige mais processamento para elaborar a resposta.

O uso do recurso de self-talk foi feito em 11 das 40 respostas com incerteza dadas ao ALiB, em 8 das 22 respostas com incerteza no BotEmbauche e em 6 respostas das 29 que expressaram incerteza no jogo Pergunte aos Universitários. As porcentagens de respostas com incerteza nas quais ocorreu self-talk foram similares nessas três situações discursivas, com porcentagem de ocorrência um pouco maior no BotEmbauche.

Quanto à duração desses recursos, ver tabela 3.

Tabela 3 - Duração média, em segundos, das pausas, prolongamentos e self-talk nas respostas com certeza e incerteza nas três situações discursivas estudadas

\begin{tabular}{cccc|ccc|ccc} 
& \multicolumn{3}{c|}{ ALiB } & \multicolumn{3}{c|}{ BotE } & \multicolumn{3}{c}{ PU } \\
\hline & pausas & prol. & s. talk & pausas & prol. & s. talk & pausas & prol. & s.talk \\
\hline Certeza & - & - & - & 0,754 & - & 0,283 & - & - & - \\
Incerteza & 0,951 & - & 1,604 & 3,454 & - & 0,735 & 0,507 & 0,413 & 1,533 \\
Legenda: prol. - prolongamentos; s. talk - self-talk.
\end{tabular}

Fonte: Elaborada pelo autor com dados da pesquisa.

Novamente é possível diferenciar o uso desses recursos quanto a sua duração, para diferenciar certeza de incerteza. No caso do corpus BotEmbauche, única situação discursiva em que houve 
V. 11 (1)

$1-23$

jan-abr

2021

pausa e self-talk na expressão da certeza, pode-se observar que a duração desses recursos na expressão da incerteza apresenta maior tempo de realização. Ou seja, é possível que a pausa e o self-talk na expressão da incerteza durem mais que na expressão da certeza, mas relativizamos esse resultado por só termos localizado uma pausa e um self-talk na certeza em todos os corpora analisados. Em relação às diferentes situações discursivas, não há uma relação padronizada para pausas e self-talk (não incluímos aqui os prolongamentos, pois estes só ocorreram em uma das situações discursivas aqui analisadas). No caso das pausas, os valores menores aparecem no jogo Pergunte aos Universitários e os maiores valores estão no corpus BotEmbauche. Novamente a pressão para responder ao jogo, situação em que ganhar um prêmio está envolvida, pode influenciar em respostas com incerteza nas quais as pausas são mais breves. No self-talk, os valores menores estão nos dados do BotEmbauche, enquanto a duração desse recurso nas respostas ao jogo televisivo e ao ALiB é maior. Como, em muitas ocasiões, o self-talk é uma repetição da pergunta, o tamanho das perguntas feitas - mais curtas no corpus BotEmbauche - pode explicar porque a duração do self-talk é menor no BotEmbauche.

Os resultados apresentados permitem concluir que a expressão da incerteza se diferencia da expressão da certeza por meio dos parâmetros prosódicos incluídos na organização temporal do discurso. Permitem ainda observar que, embora os mesmos recursos prosódicos de ordem temporal sejam utilizados para expressão da incerteza em diferentes situações discursivas, o uso de cada um desses recursos pode ser individualizado a depender da interação e de suas condições discursivas (quem são os interactantes, qual o objetivo da interação, entre outros).

\section{Considerações finais}

Embora estudos prosódicos anteriores de expressão de certeza e de incerteza tenham focalizado o parâmetro da frequência fundamental (AZEVEDO, 2007; SILVA, 2008), principalmente mostrando que um movimento melódico ascendente é associado à incerteza, os parâmetros ligados à organização temporal do discurso também constituem pistas importantes para a expressão da incerteza. Trabalhos anteriores apontaram isso, principalmente no que se refere à latência e à velocidade de fala (ANTUNES; AUBERGÉ, 2015). 
Não conhecemos trabalho anterior que tenha se concentrado somente na investigação temporal do discurso quanto à expressão de certeza ou de incerteza. Neste trabalho, focalizamos nestes parâmetros e foi possível verificar que todos os elementos da organização temporal do discurso aqui analisados resultaram em diferenças na expressão da certeza e da incerteza. Tempo de latência, velocidade de fala e recursos, como pausas, prolongamentos e self-talk, foram utilizados pelos falantes como pistas que o interlocutor usa para perceber expressividade de certeza ou de incerteza.

Desconhecíamos ainda trabalhos para o português brasileiro que comparassem a expressão dos afetos sociais certeza e incerteza em diversas situações de interação. Queremos destacar, neste trabalho, a semelhança dos recursos prosódicos usados para a expressão da certeza e da incerteza mesmo em situações discursivas diversas. No entanto, encontramos também diferenças, que mostram que o locutor adequa sua expressividade em relação à situação. No caso das respostas ao ALiB, por exemplo, como não havia tanta tensão na sociointeração, sendo o questionário uma interação menos monitorada, o tempo de latência das respostas incertas, mesmo sendo maior que nas respostas certas, não é tão longo como no programa Pergunte aos Universitários. Isso mostra que expressar certeza e incerteza se condiciona à situação discursiva, já que, sob pressão, e sob certas condições discursivas (nesse caso, ganhar prêmio em um jogo), o locutor tende a pensar mais, antes de expressar uma resposta que pode estar errada.

Desse modo, concluímos que a investigação dos parâmetros prosódicos, aliada às situações de interação, deve ser analisada, para além das medidas acústicas feitas, com a cena enunciativa que se constrói, bem como com a intenção do locutor ligada a outras especificidades de sua inserção nessa cena. Trabalhos futuros poderiam contemplar outras situações discursivas, a fim de verificar se, devido a outros fatores que compõem a enunciação, os parâmetros prosódicos para expressão de certeza e incerteza variam da mesma forma, ou mesmo se outros parâmetros são usados nessa expressividade.

\section{Referências}

ANTUNES, L. B.; AUBERGÉ, V.; SASA, Y. Certainty and uncertainty in Brazilian Portuguese: methodology of spontaneous corpus collection and data analysis. In: Proceedings of the $7^{\text {th }}$ Conference on Speech Prosody. Dublin, 2014. $\mathrm{p}$. 110-114. 
V. 11 (1)

$1-23$

jan-abr

2021

ANTUNES, L. B.; AUBERGÉ, V. Análise prosódica da certeza e da incerteza em fala espontânea e atuada. Diadorim, n. 17, v. 2, p. 212-237, dez. 2015. Disponível em: <https://revistas.ufrj.br/index.php/diadorim/article/view/4077>. Acesso em jul. 2019.

AUBERGÉ, V. Prosodie et émotion. In: Actes des XIIèmes Assises Nationales du GdR 13, 2002. p. 263-273. Disponível em: <http://sis.univ-tln.fr/gdr13/ fichiers/assises2002/papers/15-ProsodieEtEmotion.pdf $>$. Acesso em ago. 2003.

AZEVEDO, L. L. Expressão da atitude através da prosódia em indivíduos com doença de Parkinson idiopática. Tese (Doutorado em Linguística). Faculdade de Letras da Universidade Federal de Minas Gerais, Belo Horizonte, 2007.

BAKHTIN, M. Os Gêneros do Discurso. In: BAKHTIN, M. Estética da Criação Verbal. São Paulo: Martins Fontes, 1992, p. 261- 306.

BARBOSA, P. Conhecendo melhor a prosódia: aspectos teóricos e metodológicos daquilo que molda nossa enunciação. Revista de Estudos da Linguagem, Belo Horizonte, v. 20, n. 1, p. 11-27, jan./jun. 2012. Disponível em: <http://www. periodicos.letras.ufmg.br/index.php/relin/ article/view/2571/2523>. Acesso em out. de 2014.

BARBOSA, P.; MADUREIRA, S. Manual de fonética acústica experimental. São Paulo: Cortez, 2015.

BOERSMA, P.; WEENINK, D. Praat: doing phonetics by computer. Software. Versão 6.1. 2019. Disponível em: <wWw.praat.org>.

COUPER-KUHLEN, E. An introduction to English Prosody. Tübingen, Niemeyer, 1986.

CRYSTAL, D. Prosodic Systems and Intonation in English. Cambridge: Cambridge University Press, 1969.

FIORIN, J. L. Tendências da análise do discurso. Estudos Lingüísticos, v. 19, p. 173-179, 1990.

FODOR, J. D. Psycholinguistics cannot escape prosody. 2002. Disponível em: <https://www.researchgate.net/publication/2891257__ Psycholinguistics

Cannot_Escape_Prosody>. Acesso em abr. 2020.

FÓNAGY, I. Des fonctions de l'intonation: essay de sinthèse. Flambeau, n. 29, p. 1-20, 2003.

FONSECA, A. A. Pistas prosódicas e o processamento de sentenças ambíguas do tipo "SN1-V-SN2-Atributo" do português brasileiro. Dissertação de Mestrado. Belo Horizonte, Universidade Federal de Minas Gerais, 2008.

GROSJEAN, F.; DESCHAMPS, A. Analyse contrastive des variables temporelles de l'anglais et du français: vitesse de parole et variables composantes: phénomenes d'hesitation. Phonetica, n. 31, v. 3-4, p. 144-184, 1975.

HALLIDAY, M. A. K. Intonation and Grammar in British English. Mouton: The Hague, 1967. 
KRAHMER, E. J.; SWERTS, M. How children and adults produce and perceive uncertainty in audiovisual speech. In: Language and speech, vol. 48, n. 1, p. 29-54, 2005. Disponível em <https://doi.org/10.1177\%2F0023830909103164>. Acesso em 17 set. 2013.

MAC, D.; AUBERGÉ, V.; CASTELLI, E.; RILLIARD, A. Local vs. Global Prosodic Cues: Effect of Tones on Attitudinal Prosody in Cross- Perception of Vietnamese by French. Proceedings of $\mathbf{d e}^{6^{\text {th }}}$ Speech Prosody, 2012, p. 222-229.

MERLO, S.; BARBOSA, P. A. Séries temporais de pausas e de hesitações na fala espontânea. Cadernos de Estudos Linguiísticos, v. 54, n. 1, p. 11-24, 2012.

MORAES, João. A Entoação Modal Brasileira: Fonética e Fonologia. Cadernos de Estudos Lingüísticos. Campinas, n. 25, p. 25-66, 1993.

MORAES, J. From a prosodic point of view: remarks on attitudinal meaning. In: MELLO, H., PANUNZI, A., RASO, T (eds.) Pragmatics and Prosody: Illocution, modality, attitude, information patterning and speech annotation. Firenze: Firenze University Press, 2011. p. 19-38.

OLIVEIRA, M. do C. C. de et alii. O que os fonoaudiólogos e estudantes de fonoaudiologia entendem por fluência e disfluência. Revista CEFAC, São Paulo, v. 9, n. 1, jan/mar 2007.

PIKE, K. The Intonation of American English. Michigan: University of Michigan Press, 1945.

SILVA, J. P. G. A prosódia na expressão da dúvida e da certeza no português brasileiro. 171fls. Dissertação (Mestrado em Linguística). Faculdade de Letras da Universidade Federal de Minas Gerais, Belo Horizonte, 2008.

SILVA, P. C. G; SOUSA, A. P. Língua e Sociedade: influências mútuas no processo de construção sociocultural. Revista Educação e Emancipação, São Luís, v. 10, n. 3, set/dez.2017, p. 260-285.

WICHMANN, A. Attitudinal Intonation and the Inferential Process. In: Proceedings of the $\mathbf{1}^{\text {st }}$ Speech Prosody. Aix-en-Provence, 2002.

ZELLNER, B. Pauses and the temporal structure of speech. In: KELLER, E. (ed.) Fundamentals of speech synthesis and speech recognition. Chichester: John Wiley, 1994. p. 41-62. 